of Technological and Biomedical Materials by Photothermal Spectroscopy

Otto Wolfbeis (University of Regensburg, Institute of Analytical Chemistry, Chemo- and Biosensors, Germany): Chemical Sensing and Biosensing Using Advanced Fluorescent (Nano)materials

During the Conference Juergen Popp (FriedrichSchiller University Jena, Institute of Physical Chemistry and Institute of Photonic Technology, Germany) was awarded the Robert Kellner Lecture Prize established by DAC of EuCheMS and kindly sponsored by Springer Verlag. After laudation Paul Worsfold delivered a lecture entitled: The many facets of Raman spectroscopy for biomedical analysis.

On Tuesday and Wednesday participants of the Conference had opportunity to take part in vendor seminars organized by companies:

Perlan Technologies: 27 August 2013 (about 40 participants), Emilia Fornal: Analysis of cathinone-based drugs by LC/Q-TOF; Sebastien Sannac: Applications with ICP-QQQ: Expand the frontiers of element analysis with the Agilent 8800 ICP-MS/MS

Shimadzu: 28 August 2013 (abou 90 participants), Danilo Sciarrone: Enhanced elucidation of complex samples by using a multidimensional LC-GC/MS system; Franz Kramp: The new Tracera GC system: Trace analysis with plasma techno/ogy; Marion Egelkraut-Holtus: State of the art in FTIR spectroscopy

The social program of Euroanalysis XVII consisted of a welcome party in the Main Building of Warsaw University of Technology (Sunday, 25 August, Beer Barbecue Party in Gościniec Wiecha, located in heritage park outside Warsaw (Monday, 26 August), a concert in Teatr Polski performed by the Song and Dance Ensemble of Warsaw University of Technology (Tuesday, 27 August) and Gala Dinner in the Great Hall of Warsaw University of Technology (Wednesday, 28 August). During closing ceremony, awardees of Polish Chemical Society prizes for oral presentation in the field of separation techniques, as well as Springer prizes for best poster presentations were announced. They were:

PCS prizes: Lucas Sternbauer, Johannes Kepler University of Linz, Austria; Sylwia Magiera, Silesian University of Technology, Poland.

Springer prizes: Agnieszka Moos, Jana Jaklova Dytrtova, Magdalena Matczuk, Magdalena BuszewskaFarajta, Jolanta Kochana, Katarzyna Witkoś.

Maciej Jarosz<mj@ch.pw.edu.pl> is Chair of Analytical Chemistry at Warsaw University of Technology in Warsaw, Poland

\section{Environmental Best Practices}

An international conference was held in Olsztyn, 8-12 September 2013, called Biorefinery-Biobased Value Chains and Sustainable Development. This was the fourth conference in a cycle of the International Environmental Best Practices Conferences raising contemporary research and questions and outlining development prospects for future environmental science research. The conference was co-organized by the University of Warmia and Mazury in Olsztyn, Poland and the University of Applied Sciences in Offenburg, Germany.

This conference attracted about 100 participants, including scientists from Germany, the Netherlands, France, Greece, Czech Republic, Norway, Russia, Singapore, Australia, USA, and Poland. The conference included 83 papers: 42 talks and 41 poster presentations.

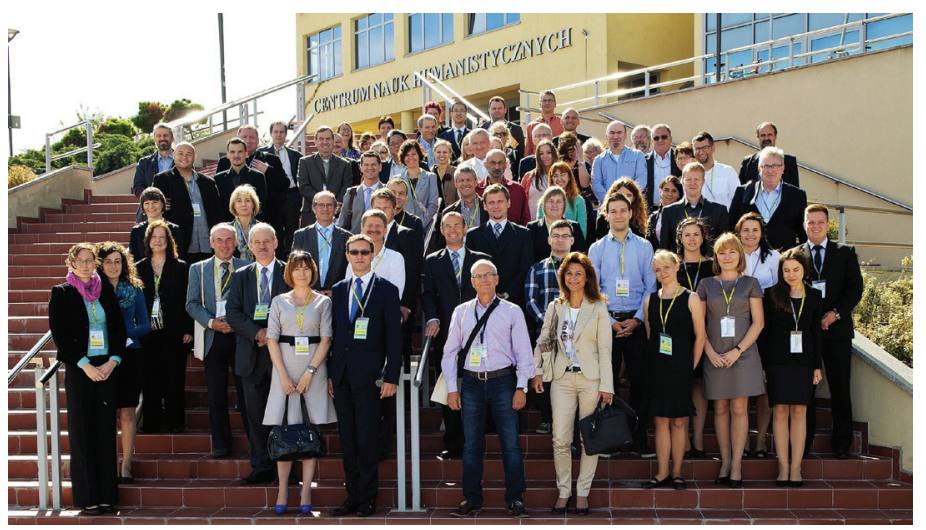

The 4th International Environmental Best Practices Conference "Biorefinery: Biobased Value Chains and Sustainable Development," Olsztyn, Poland, 8-12 September 2013

The subject of the conference concerned the concept of biorefinery. In particular it focused on development and research prospects of biomass production and its conversion using biotechnology. These practices create a spectrum of bioproducts while building chains of added value.

The biorefinery concept is the real research challenge for today because it will create the future bioeconomy market. Firstly, the development of this concept requires an interdisciplinary research approach to promote synergistic scientific achievements. Green, red, blue, and white biotechnology, chemistry, technical, agricultural, environmental, social, and economic sciences will all contribute to this. Secondly, research effects associated with biorefineries, new biorefinery processes and products implemented in the future 
market portfolio will integrate three fundamental areas of sustainable development: environment, economy and society.

The conference summarized research achievements and new trends in many interrelated aspects concerned with bioprocesses and bioproducts. They were discussed in eight consecutive research sessions. There was also a workshop on research-funding programs associated with biorefinery concepts, which are accessible in the USA, the EU, and Poland.

\section{Biorefinery - Research Progress and Opportunities}

- biorefinery feedstock

- development of biorefinery processes towards the added value chains.

Feedstock

- derived from primary (agricultural, forestry, aquaculture production), secondary (residues from agricultural streams) and tertiary sources (post-consumer residue streams)

- new production technologies

- biomass acquisition methods

- logistics

- energy and economic potential.

Genetics and Biotechnology

- recent advances in molecular biology, genetics, genomics and DNA sequencing

- genetic engineering of plants for biorefinery feedstock

- possible contributions of modern plant genetics and breeding technologies in the improvement of pre-processing of biomass.

Biomass pretreatment

- recent developments in the existing pretreatment processes (including steam explosion, solventbased, acidic and alkaline thermal processes and enzymatic).

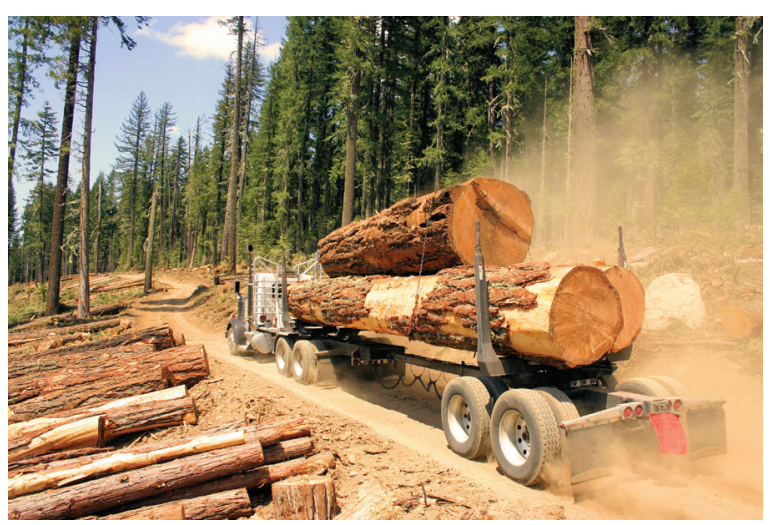

Bioprocesses and bioproducts

- major pathways of the production of materials and chemicals (including carbohydrates $\mathrm{C} 5$ and $\mathrm{C} 6$, oils, hemicellulose)

- lignin and lignin hydrolysis based products

- innovative approaches relying on microbial transformations, green chemical processes and enzymatic transformations.

Valorization of waste, effluents and by-products by microorganisms and enzymes

- optimization of extraction protocols to recover valuable molecules from waste (including polysaccharides, lipids, antioxidants, enzymes)

- application of enzymes or microorganisms to improve bioconversion and biotransformation of residue to valuable products (including polymers (PHA), biosurfactants, ethanol, enzymes, lipids and proteins)

- application of metagenome, protein engineering and directed evolution methods in the synthesis of final products which may be eventually used in food processing, cosmetics and pharmacological industries.

Thermal, chemical and biochemical conversion of biomass to useful energy

- biorefinery processes which create additional value from process residues by thermal, chemical, and biochemical treatment (including processing of advanced fuels like hydrogen via organic fuel cell or fermentation, 2nd generation biodiesel via chemical F-T process).

Environmental impact

- possible adverse effects caused by the biorefinery industry and solutions to the problems

- environmental pathways for wastes, hazardous chemicals and particles

- environmental toxicology and risk assessment (including cellular and biochemical toxicology, biodiversity-based surveys, hot spot contamination and health outcomes).

The major conclusion from this highly successful conference was that attaining the maximum value of biomass requires an interdisciplinary research approach and a thorough multilayer analysis. The anticipated progress in research, particularly associated with industrial biotechnology and chemistry, will have a pivotal impact on processing of new bioproducts and the successful development of the future bioeconomy market. Today, we are still only setting out on the challenging and fascinating scientific pathway.

Prof. Dr. Janusz Gołaszewski, University of Warmia and Mazury in Olsztyn, Poland 